\title{
IMPACTO AMBIENTAL SONORO E VISUAL NA REGIÃO CENTRAL DO MUNICÍPIO DE GOIÂNIA - GO
}

\author{
Italo Fernandes de Lima ${ }^{(a)}$, Maycon Penha da Silva ${ }^{(b)}$ \\ (a) Instituto de Estudos Socio-Ambientais, Universidade Federal de Goiás, italofernandeslima@gmail.com \\ (b) Instituto de Estudos Socio-Ambientais, Universidade Federal de Goiás, maycon.ufg@ gmail.com
}

Eixo: Uso e ocupação das terras e legislação ambiental

\begin{abstract}
Resumo
Dentro da problemática ambiental talvez a poluição sonora e visual sejam as mais significativas, pois não dá consciência às vítimas do mal que fazem à saúde. Objetivou-se, com a realização deste estudo, avaliar os impactos ambientais vinculados à poluição sonora e visual presente no centro urbano do município de Goiânia-GO. A poluição sonora foi avaliada por meio dos níveis de decibéis $(\mathrm{dB})$, que foram coletados por um decibelímetro e a poluição visual foi avaliada por meio de registros fotográficos tirados no entorno dos pontos coletados. As pessoas que transitam nestes locais estão sujeitas a desenvolver problemas de saúde em função da poluição sonora e visual, que de acordo com a legislação, podem ser caracterizados como locais insalubres. A solução eficaz para esses dois problemas caberia ao Estado, com um planeamento dos espaços urbanos de forma a harmonizar o desenvolvimento das cidades com a qualidade ambiental.
\end{abstract}

Palavras chave: Impactos ambientais; Poluição sonora; Poluição visual; Áreas urbanas.

\section{Introdução}

Impacto ambiental se refere a resultados das ações humanas sobre o ambiente, estas ações podem ter uma ou mais causas. Muitas vezes as causas dos impactos ambientais têm relação com a poluição ambiental. O impacto ambiental pode ser positivo ou negativo, porém a poluição sempre será negativa, uma vez que ela é uma degradação da qualidade ambiental.

Dentro da problemática ambiental talvez a poluição sonora seja a mais significativa, pois não dá consciência às vítimas do mal que faz à saúde. Essa poluição vem se agravando nos últimos anos, exigindo soluções que controlem seus efeitos na qualidade de vida dos cidadãos.

O rápido crescimento populacional de Goiânia aconteceu de forma desordenada e, paralelamente ao crescimento, verificou-se relevante aumento das pressões sobre o meio ambiente, sendo a poluição sonora, segundo Pasqualetto (2001) a terceira mais grave, só perdendo para a poluição do ar e da água. 
Diante desta situação, tem-se um quadro preocupante, uma vez que o ambiente urbano está susceptível a este tipo de poluição. Neste sentido objetivou-se avaliar os impactos ambientais vinculados à poluição sonora e visual presente no centro urbano do município de Goiânia e, também, fazer uma comparação com algumas áreas isoladas, incluídas na área de estudo, onde aparentemente possuem níveis de ruídos menores.

\section{Revisão bibliográfica}

Mesmo na antiguidade o ruído era um problema para o homem. Já na Antiga Roma existiam restrições para o ruído emitido pelas rodas das carruagens puxadas por cavalos que rodavam pelos caminhos empedrados e que causava incômodo e transtorno no sono (WHO, 1999). Existem também outras referências, como por exemplo, um decreto do século XVI na Inglaterra o qual proibia os maridos de bater em suas esposas após as dez da noite para não perturbar os vizinhos com os gritos (SANTIAGO, 1992; SUÁREZ, 2002, apud MARDONES, 1999).

De acordo com Mardones (1999) com o começo da Era Industrial, no século XIX começa a preocupação pelos efeitos nocivos do ruído como perda de audição em pessoas nos postos de trabalho com altos níveis de ruído gerado por máquinas. E nesta mesma época que começa a modificação estrutural urbana das cidades, surgem os bairros da classe operária afastados das cidades e há o nascimento de linhas ferroviárias localizadas geralmente perto das residências gerando incômodo na população (SANTIAGO, 1992; SUÁREZ, 2002, apud MARDONES, 1999).

Hoje em dia o ruído ambiental causado pelo tráfego veicular junto com o das atividades industriais e recreativas são um dos principais problemas ambientais e a origem de um número cada vez maior de denúncias por parte da população (MARDONES, 1999). Uma cena bem recorrente observada na região central do município de Goiânia.

De acordo com a Organização Mundial da Saúde, na União Europeia aproximadamente $40 \%$ da população é exposta a ruído de tráfego rodoviário com níveis de pressão sonora excedendo os $55 \mathrm{~dB}(\mathrm{~A})$ no período diurno e $20 \%$ a níveis superiores a $65 \mathrm{~dB}(\mathrm{~A})$. Já durante o período noturno mais de $30 \%$ da população é exposta a níveis superiores a $55 \mathrm{~dB}(\mathrm{~A})$, provocando distúrbios no sono (WHO, 1999). Considerando todas as fontes de ruído de transporte, estima-se que mais da metade da população mora em zonas nas quais o conforto acústico não é assegurado em suas residências (MARDONES, 1999).

Na realidade brasileira há pouca disponibilidade de dados sobre a exposição sonora da população. De acordo com levantamentos sonoros realizados em algumas cidades, como em Florianópolis-SC (NARDI, 2008) e Aracaju-SE (GUEDES et al, 2011) nota-se que a população é exposta a níveis de ruídos elevados. 
De acordo com Gregory et al (2012), os sons que o ouvido humano pode perceber tanto podem ser agradáveis, quanto desagradáveis e que causam desconforto; estes então são denominados ruídos. O limite entre som e ruído tem origem psicológica, portanto, depende da sensação que causa no indivíduo, do tempo de duração ou exposição a esse, do tipo de fonte sonora, do estado de espírito e até de como pode ativar sua memória auditiva (GRANDJEAN, 1998, apud, GREGORY, 2012).

O ruído excessivo pode comprometer seriamente a saúde das pessoas, influindo diretamente em seu cotidiano. Os efeitos do ruído podem ocasionar diversos problemas de saúde, quais sejam: deficiência auditiva, insônia, queda no rendimento, transtorno no comportamento social, como agressividade ou passividade, dor e fadiga, problemas na fala, estresse e suas consequências (WHO, 2011).

Assim, ressalta-se a importância de realizar tal estudo, visto que a expansão de Goiânia aconteceu de forma desordenada e com um planejamento feito para menos da metade da população atual. Por esses motivos torna-se cada vez mais necessário criar formas que evidenciem os problemas de modo a informar e quantificar a exposição aos riscos. Nesse contexto, o levantamento de dados pode criar um diagnóstico do problema, evidenciá-lo e ainda propor soluções a curto e longo prazos.

\section{Materiais e métodos}

Foram avaliados vinte e um dentro da área de estudo, sendo estes pontos georreferenciados a partir de um GPS visitados no dia 19 de outubro de 2016 no período da manhã.

A área de estudo abrange a região central do município de Goiânia. O município originalmente projetado para 50.000 habitantes (ARCA, 2003), possui mais de 1.302.001 habitantes somente em sua área territorial (INSTITUTO BRASILEIRO DE GEOGRAFIA E ESTATÍSTICA - IBGE, 2010). Considerando-se a área de conurbação, há um acréscimo de aproximadamente $10 \%$ nessa população, refletindo no aumento dos problemas ambientais para a administração pública.

Os pontos coletados são específicos e pensados para a região que abrange áreas com múltiplas atividades. Foram coletados pontos na Avenida Anhanguera, Avenida Goiás, Avenida Tocantins, Alameda dos Buritis, Rua 1, Rua 3, Rua 8, Rua 13, Rua 16, Praça Cívica, Avenida 85, Rua 100 e Rua 101. Que incluem pontos em áreas residenciais, escolares, comerciais, administrativas e áreas de recreação.

Para avaliar os impactos ambientais vinculados à poluição sonora e visual presentes na área estudo são necessários conhecer o conceito destes termos para melhor compreensão dos resultados. 


\subsection{Impacto ambiental}

A resolução do Conselho Nacional do Meio Ambiente - CONAMA n 1 em seu Artigo $1^{\circ}$ (1986) considera impacto ambiental como sendo:

Qualquer alteração das propriedades físicas, químicas e biológicas do meio ambiente, causada por qualquer forma de matéria ou energia resultante das atividades humanas que, direta ou indiretamente, afetam:

A saúde, a segurança e o bem-estar da população;

As atividades sociais e econômicas;

A biota;

As condições estéticas e sanitárias do meio ambiente;

A qualidade dos recursos ambientais;

\subsection{Poluição}

A lei nº 6.938 (BRASIL, 1981) que trata da Política Nacional de Meio Ambiente, traz a definição de poluição:

III - poluição, a degradação da qualidade ambiental resultante de atividades que direta ou indiretamente:

a) prejudiquem a saúde, a segurança e o bem-estar da população;

b) criem condições adversas às atividades sociais e econômicas;

c) afetam desfavoravelmente a biota;

d) afetem as condições estéticas ou sanitárias do meio ambiente;

e) lancem matérias ou energia em desacordo com os padrões ambientais estabelecidos.

\subsection{Poluição Sonora}

Poluição sonora é o conjunto de ruídos provenientes de fontes sonoras manifestadas ao mesmo tempo num ambiente qualquer, sendo prejudicial à saúde dos seres vivos. Os valores obtidos foram comparados com o Nível de Critério de Avaliação (NCA) para ambientes externos (Tabela 1), em decibéis, pela Norma Brasileira (NBR) 10151 (ABNT, 2000). 
Tabela I- Nível de critério de avaliação NCA para ambientesexternos, em $\mathrm{Db}(\mathrm{A})$

\begin{tabular}{lcc}
\hline \multicolumn{1}{c}{ TIPOS DE ÁREAS } & DIURNO & NOTURNO \\
\hline Áreas de sítios e fazendas & 40 & 35 \\
Áreas estritamente residencial urbana ou de hospitais e escolas & 50 & 45 \\
Área mista, predominantemente residencial & 55 & 50 \\
Área mista, com vocação comercial e administrativa & 60 & 55 \\
Área mista, com vocação recreacional & 65 & 55 \\
Área predominantemente industrial & 70 & 60 \\
\hline
\end{tabular}

Fonte: NBR 10151(2000)

\subsection{Poluição Visual}

Poluição visual é o excesso de elementos ligados à comunicação visual dispostos em ambientes urbanos, especialmente em locais comerciais. O Código de Posturas do Município de Goiânia (GOIÂNIA, 1992) estabelece que:

Art.139 - É proibida a publicidade ou propaganda por meio de faixas de tecidos ou de material de qualquer natureza, quando afixadas em postes, árvores da arborização pública, fachadas ou muros. Parágrafo único - A proibição de que trata o presente artigo não se aplica aos casos de campanhas educativas, filantrópicas e cívicas, quando promovidas pelo Governo, ressalvada a utilização da arborização pública e da sinalização de trânsito vertical e semafórica.

Art.142 - Os letreiros, placas e luminosos instalados sobre as marquises dos edifícios não poderão possuir comprimento superior às mesmas, devendo suas instalações serem restritas à testada do estabelecimento. Parágrafo único - Os letreiros, placas e luminosos de que trata o presente artigo, quando instalados em edifícios com mais de um pavimento, não poderão ultrapassar a altura do peitoril da janela do primeiro andar ou, se for o caso da sobreloja.

Art.144 - Nos toldos instalados na testada dos edifícios, a publicidade ficará restrita ao nome, telefone, logotipo e atividade principal do respectivo estabelecimento.

Art. 150 - É expressamente proibida a inscrição e a afixação de anúncios e publicidade de qualquer natureza nos seguintes casos:

I - quando, pela sua espécie, provoquem aglomerações prejudiciais ao trânsito público;

II - quando forem ofensivas à moral ou contiverem referências desprimorosas a indivíduos, estabelecimentos, instituições ou crenças;

III - quando o vernáculo for utilizado incorretamente;

IV - quando constituídos por inscrição na pavimentação, das vias, meios-fios e calçadas;

$V$ - em postes da rede elétrica, gradis, colunas e nos abrigos para passageiros do transporte urbano; 
VI - nas árvores da arborização pública;

VII - em monumentos que constituam o patrimônio histórico;

VIII - em estátuas, parques públicos, praças e jardins;

$I X$ - quando equipados com luzes ofuscantes;

$X$ - em bancas de jornais e revistas e similares;

$X I$ - em passagens de nível;

A poluição sonora foi avaliada por meio dos níveis de decibéis, que foram coletados por um decibelímetro e a poluição visual foi avaliada por meio de registros fotográficos tirados no entorno dos pontos coletados. Após obter os dados em campo, foram confeccionados: mapa, gráficos no Excel e montagens com as fotos obtidas em campo, com o intuito de melhor visualização dos dados. Posteriormente foi confeccionado o relatório contendo as análises de todos os dados obtidos e avaliados a partir da visita a campo na área de estudo.

\section{Resultados}

Acima de $60 \mathrm{~dB}$ o barulho é considerado como incomodativo. A OMS estima que se torna perigoso a partir de 85-90 dB sobre uma duração de 8 horas (DEUOX e DEUOX, 1996). A Lei Complementar 132 estabelece o limite máximo de $65 \mathrm{~dB}$ para a área central da capital no período diurno. E como se pode observar os níveis sonoros apresentados (Figura 1 e Gráfico 1) estão bem acima do permitido, ultrapassando mais de $50 \%$ em alguns pontos pela legislação municipal.

Em quase $100 \%$ dos pontos coletados pode observar-se que o principal agente causador da poluição sonora são os veículos automotores. Nas áreas com uma predominância residencial, mesmo possuindo um menor número de ruído na medição com o decibelímetro, a influência do forte trafego das avenidas próximas afetam o resultado esperado elevando o nível de ruído para acima da média permitida. 


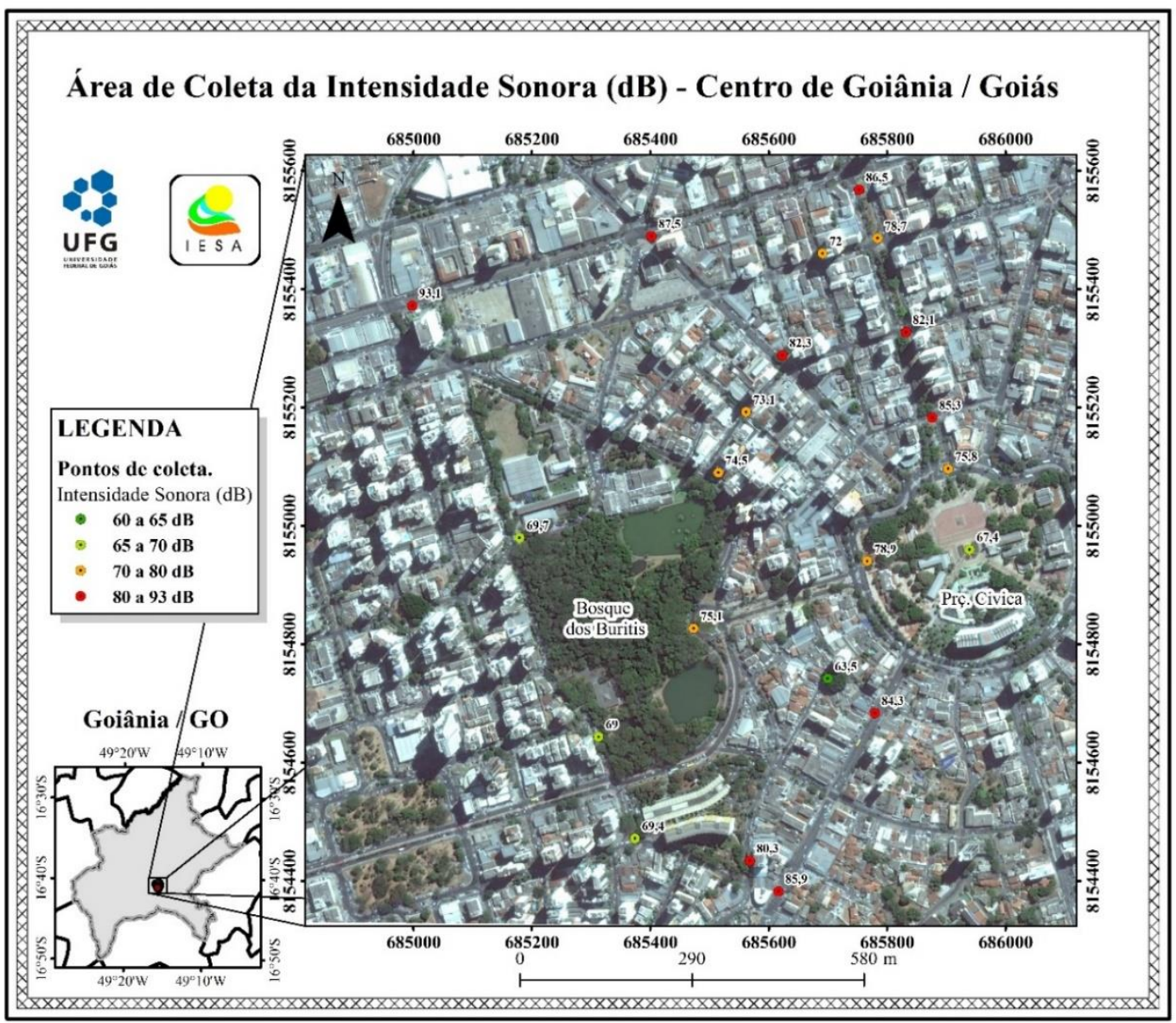

Figura 1: Área de coleta dB

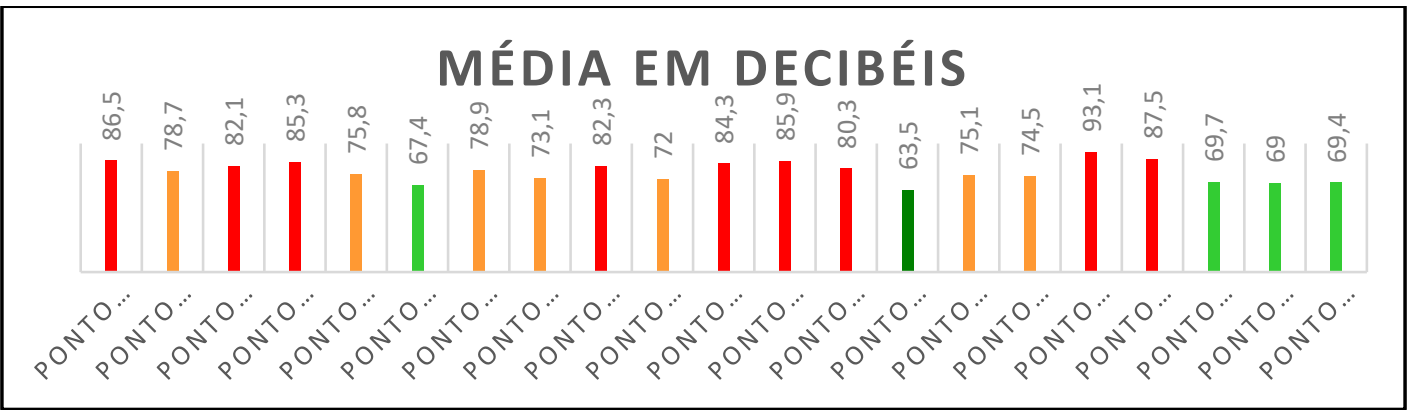

Gráfico 1: Media de decibéis

De acordo com Deuox e Deuox o barulho da circulação dos veículos automotores depende de muitos parâmetros: débito do trânsito, velocidade dos veículos, proporção de caminhões, mudança de um regime do motor. Alguns cruzamentos urbanos são "pontos críticos" com um nível sonoro excessivo e comprometedor. O nível sonoro ficou na faixa de $80 \mathrm{~dB}$ e as pessoas que circulam por estes locais e ficam 
expostas por longos períodos de tempo podem apresentar efeitos psicológicos (depressão, solidão e ansiedade).

Sendo assim existem medidas que podem ser tomadas com a finalidade de reduzir o nível de intensidade sonora: o remanejamento do trânsito, com a instalação de sinaleiros sincronizados permitindo o fluxo direto de veículos, a criação de uma legislação especifica para fabricação de motores automotivos silenciosos, educação ambiental conscientizando os motoristas a usarem a buzina somente quando necessário, uma fiscalização rígida capaz de fazer cumprir pelo menos a legislação já existente, dentre outras.

O movimento de veículos quanto mais livre e direto for, produzirá menor nível de poluição do ar e sonora, sem considerar a economia de tempo e combustível. Por isso, seria possível obter redução significativa, sobretudo dos níveis de poluição sonora decorrentes do tráfego de veículos tendo como base um planejamento urbano eficaz que valorizando a descentralização, com acessibilidade facilitada e cujo imóvel não fique localizado nas adjacências dos principais corredores de tráfego da cidade, ou seja, com um recuo frontal mínimo entre os imóveis e os corredores de tráfego não haverá superfícies refletoras capazes de prejudicar a dissipação de ruídos.

Em relação às fontes pontuais de poluição visual (Figura 2) foram encontradas: cartazes de propaganda colados em postes, calçada e paredes; lixos transbordando pela lixeira e lixo jogado no chão; fiação solta; pichação nas paredes, muros e faixadas de lojas; cartazes de propagandas chamativos nas faixadas das lojas; produtos das lojas espalhados pelas calçadas; propagandas por meio de faixas; manequins espalhadas por toda calçada; vendedores ambulantes pelas calçadas e entorno. 


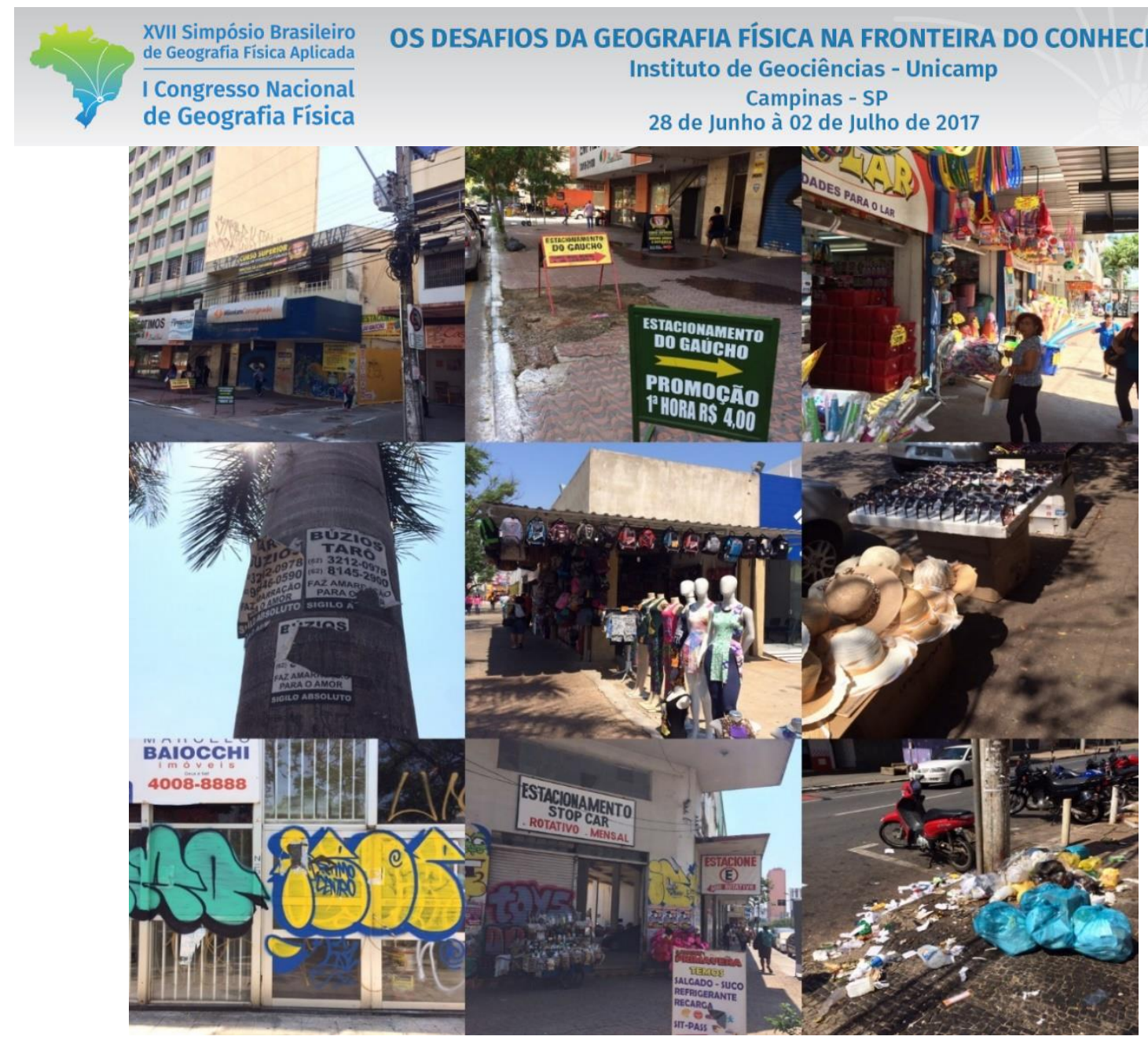

Figura 2: Imagem das fontes pontuais de poluição visual coletados nos pontos no dia 19 de outubro de 2016.

Os impactos ambientais vinculados à poluição sonora e visual de ambos os pontos analisados em estudo estão diretamente relacionados com aumento crescente das áreas urbanas, o consumo exagerado de bens materiais e a produção constante de lixo.

Dentre os principais impactos ambientais que ocorrem nestas avenidas, podemos citar: inundações, doenças na população e em outros seres vivos, diminuição de qualidade de vida etc.

As inundações podem ocorrer devido ao acúmulo de lixo de propagandas impressas e desprezos de objetos de lojas comerciais.

A poluição sonora se torna maléfica para a população a partir de seu convívio diário com o barulho, podendo causar problemas de saúde, como neurose e a perda gradativa da audição em longo prazo de tempo. Já a poluição visual não é diretamente maléfica a saúde, porém agride a sensibilidade humana e prejudica a sinalização de trânsito, podendo causar problemas de segurança. 


\section{Considerações finais}

Observando os resultados obtidos, a legislação e a revisão bibliográfica conclui- se que todos os locais analisados, apresentam nível sonoro em desconformidades com a legislação, e podem ser caracterizados como locais insalubres, pois os níveis sonoros obtidos estão bem acima dos níveis de critérios. As pessoas que transitam nestes locais estão sujeitas a desenvolver problemas de saúde em função da poluição sonora e visual.

Cabe ao Estado implementar o planejamento dos espaços urbanos de forma a harmonizar o desenvolvimento das cidades com a qualidade ambiental.

\section{Bibliografia}

ASSOCIAÇÃO BRASILEIRA DE NORMAS TÉCNICAS. NBR 10151: Acústica - Avaliação do ruído em áreas habitadas, visando o conforto da comunidade - Procedimento. Rio de Janeiro: ABNT, 2000.

BRASIL. Presidência da República. Casa Civil. Subchefia para Assuntos Jurídicos. Dispõe sobre a Política Nacional do Meio Ambiente, seus fins e mecanismos de formulação e aplicação, e dá outras providências. Lei $\mathbf{n}^{\mathbf{0}} \mathbf{6 . 9 3 8 , ~ d e ~} 31$ de agosto de 1981. Disponível em: < http://www.planalto.gov.br/ccivil_03/LEIS/L6938.htm>.

DEÓUX, P. e S. DEÓUX. O Barulho. Ecologia é a saúde. Lisboa: Instituto Piaget, 1996. p. 217-244.

GOIÂNIA. Lei Complementar n 014, de 29 de dezembro de 1992. Institui o Código de Posturas do Município de Goiânia e dá outras providências.

RESOLUÇÃO DO CONAMA $\mathbf{n}^{\mathbf{0}}$ 001, de 23 de janeiro de 1986 . Disponível em: < http://www.mma.gov.br/port/conama/res/res86/res0186.html>

GREGORI, J. M. M. H.; GREGORI, A. M. M. H.; CASAGRANDE JUNIOR, E. F. Avaliação de conforto acústico ambiental em edificação sustentável - Estudo de caso: Escritório Verde - Curitiba/PR. In: VIII CNEG - Congresso Nacional de Excelência em Gestão, Niterói, Rio de Janeiro, 2012.

GUEDES, I. C. M.; BERTOLI, S. R.; ZANNIN, P. H. T. Influence of urban shapes on environmental noise: A case study in Aracaju - Brazil. Science of the Total Environment, 412-413, 66-76, 2011.

MARDONES, M. D. M. Mapeamento dos níveis de ruído em Copacabana, Rio de Janeiro, através de simulação computacional. Dissertação de Mestrado em Ciências em Engenharia Mecânica. 59f. Instituto Alberto Luiz Coimbra de Pós-graduação e Pesquisa de Engenharia (COPPE) da Universidade Federal do Rio De Janeiro, Rio de Janeiro, Brasil, 2009.

NARDI, A. S. L. V. Mapeamento Sonoro em Ambiente Urbano. Estudo de Caso: Área Central de Florianópolis. Dissertação de Mestrado em Arquitetura e Urbanismo. 108f. Universidade Federal de Santa Catarina, UFSC, Brasil, 2008.

PASQUALETTO, A. Níveis de ruídos no campus II da Universidade Católica de Goiás. Estudos Vida e Saúde, Goiânia: UCG, v. 28, n.2, p 301-309, mar/abr. 2001.

WORLD HEALTH ORGANIZATION, WHO 1999. Guide-lines for comunity noise. Edited by Birgitta Berghund, Thomas Lindvall, Dietrich H. Schela. Disponível em: 〈http://www.who.int/docstore/peh/noise/guidelines2.html>. Acesso em: 09 de nov. 2016.

WORLD HEALTH ORGANIZATION, WHO 2011. Regional Office for Europe. Disponível em: <http://www.euro.who.int/en/what-we-do/health-topics/environment-andhealth/noise>. Acesso em: 09 de nov. 2016. 


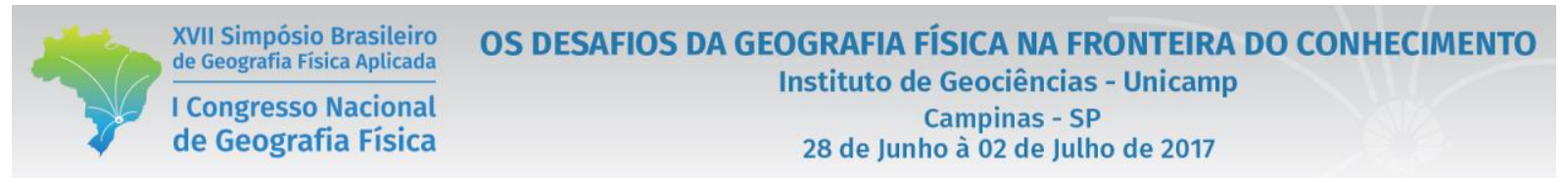

